\title{
APLIKASI ALGORITMA FEED FORWARD BACKPROPAGATION UNTUK BEBAN LISTRIK HARI LIBUR PADA TIPE BEBAN ANOMALI
}

\author{
Linda Faridah ${ }^{1}$, M Aris Risnandar ${ }^{2}$, Imam Taufiqurrahman ${ }^{3}$,Andri Ulus R \\ Program Studi Teknik Elektro, Tasikmalaya, Indonesia \\ Email : lindafaridah@usil.ac.id
}

\begin{abstract}
Abstrak. Load pattern for holiday have significant differenct from weekday day, so that require special prediction. This research have purpose to test the performance feed forward backpropagation to know accuracy level of load forecasting for holiday anomalous load. Learning algorithm used feed forward backpropagation from artificial neural network with matlab. Load forecasting optimization is change learning rate and some of learning input. The reasult of this reasult showed learning input give best reasult on mean but difference from that value is small, so learning rate variation small affected at learning
\end{abstract}

Keywords : Load forecasting, Feed Forward Backpropagation, Artificial Neural Netwotk, Learning rate, Learning input

Abstrak

Pola beban listrik hari libur memiliki perbedaan yang mencolok dengan pola beban listrik pada hari normal, sehingga memerlukan prediksi secara khusus. Penelitian ini bertujuan menguji performa algoritma feed forward backpropgation untuk mengetahui tingkat akurasi prediksi beban pada hari libur tipe beban anomali. Algoritma pembelajaran yang digunakan adalah feed forward backpropagation dari jaringan syaraf tiruan dengan menggunakan software matlab. Optimasi prediksi dilakukan dengan mengubah nilai learning rate dan jumlah input pembelajaran. Hasil penelitian memperlihatkan bahwa input pembelajaran memberikan dampak terhadap tingkat akurasi prediksi, sedangkan variasi learning rate memberikan hasil terbaik pada nilai tengah tetapi jarak antara nilai tersebut tidak begitu jauh sehingga variasi learning rate tidak begitu berpengaruh pada proses pembelajaran.

Kata kunci : Prediksi beban, Feed Forward Backpropagation, Jaringan syaraf tiruan, Learning rate, Jumlah input

\section{PENDAHULUAN}

Penggunaan beban listrik dari waktu ke waktu mengalami peningkatan. Hampir $3-7 \%$ beban meningkat dalam pertahun dan sudah terjadi selama bertahun - tahun [1]. Listrik tidak dapat disimpan dalam skala yang besar dan tidak dapat digantikan oleh sumber lainnya [2]. Oleh karena itu harus adanya penyesuaian antara total daya yang dikeluarkan pembangkitan dengan permintaan daya dari konsumen. Prediksi beban adalah salah satu cara untuk membantu dalam hal perencanaan pembangkitan maupun pengeluaran energi listrik [3]. Prediksi beban listrik jangka pendek bertujuan untuk memprediksi beban listrik pada jangka waktu menit, jam, hari atau minggu

Berikut ini beberapa perkembangan metode yang digunakan dalam prediksi beban listrik yaitu: Tahun 1968, Matthewan menggunakan Techniques for load prediction in the electricity-supply industry" [4]. Tahun 1971, Christiaanse menggunakan Exponential Smoothing [5]. Tahun 1987, Hagan menggunakan time series [6]. Tahun 1991, Lambert menggunakan sistem fuzzy [7]. Tahun 1992. KY lee menggunakan artificial neural network [8]. Tahun 1993, Ping Yan Wang mengkombinasikan artificial neural network dan fuzzy logic [9]. Tahun 1996, Hong-Tzer menggunakan ARMAX [10]. Tahun 1995, M Y Cho menggunakan ARIMA [11]. Tahun 1999, Mori menggunakan Fuzzy inverence [12]. Tahun 2006, R.R.R de Aquaimo menggunakan a hybrid intelligent system [13]. Tahun 2009, Dica menggunakan short-term forecasting of wind power [14]. Tahun 2009, Cameron menggunakan Smarter smart grid. Tahun 2010, Chen Liu menggunakan
Kernel recursive least-squares algorithm [15]. Tahun 2012 , Meijun menggunakan Model of grid-connected photovoltaic and power flow analysis [16]. Metode tersebut biasanya dilakukan pada prediksi beban untuk hari normal, pola beban untuk hari khusus seperti hari libur dan akhir pekan cenderung diabaikan dalam beberapa penelitian [17] Selama beberapa tahun terakhir, jaringan syaraf tiruan banyak digunakan dalam memecahkan masalah prediksi beban (Shayeghi et al., 2010). Jaringan syaraf tiruan pertama kali digunakan dalam forecasting tahun 1992 oleh KY lee (Lee et al., 1992). Dalam perkembangannya ada beberapa pendekatan dalam artificial neural network yaitu dengan backpropagation, genetic algorithm dan particle swarm optimization.

Pada penelitian kali ini peneliti mengembangkan metode artificial neural network dengan algoritma backpropagation dan pendekatan multilayer feed forward. Berbeda dengan penelitian sebelumnya yang menggunakan data beban hari kerja, akhir pekan dan libur nasional, kali ini penelitian dilakukan pada hari khusus (hari libur nasional cuti bersama) yang memiliki tipe beban anomali dan untuk mendapatkan hasil yang maksimal peneliti melakukan optimasi pada nilai learning rate dan jumlah input sehingga hasilnya bisa lebih akurat dan tingkat akurasinya tinggi.

\section{METODE}

Data historis yang digunakan untuk memprediksi beban listrik jangka pendek yaitu mengggunakan data pengeluaran beban listrik dari PT. PLN (persero) Area II Jawa Barat tahun 
2013-2014. Pelatihan yang dipakai untuk prediksi yaitu menggunakan data beban anomali. Data beban anomali diambil dari data beban libur nasional cuti bersama yang mempunyai demand $>4000 \mathrm{MW}$ dan demand $<2000 \mathrm{MW}$. Flowchart dalam penelitian berbasis Algoritma Feed Forward Backpropagation Jaringan Syaraf Tiruan .

Penelitian kali ini menggunakan algoritma feed forward backpropagation jaringan syaraf tiruan dengan 3 lapisan tersembunyi dan 1 lapisan output. Fungsi aktivasi yang digunakan yaitu sigmoid biner, sigmoid biopolar dan fungsi identitas. Data pelatihan untuk forecasting ini menggunakan data beban listrik anomali dengan jumlah 15 data. Flowchart dalam penelitian berbasis Algoritma Feed Forward Backpropagation Jaringan Syaraf Tiruan adalah sebagai berikut

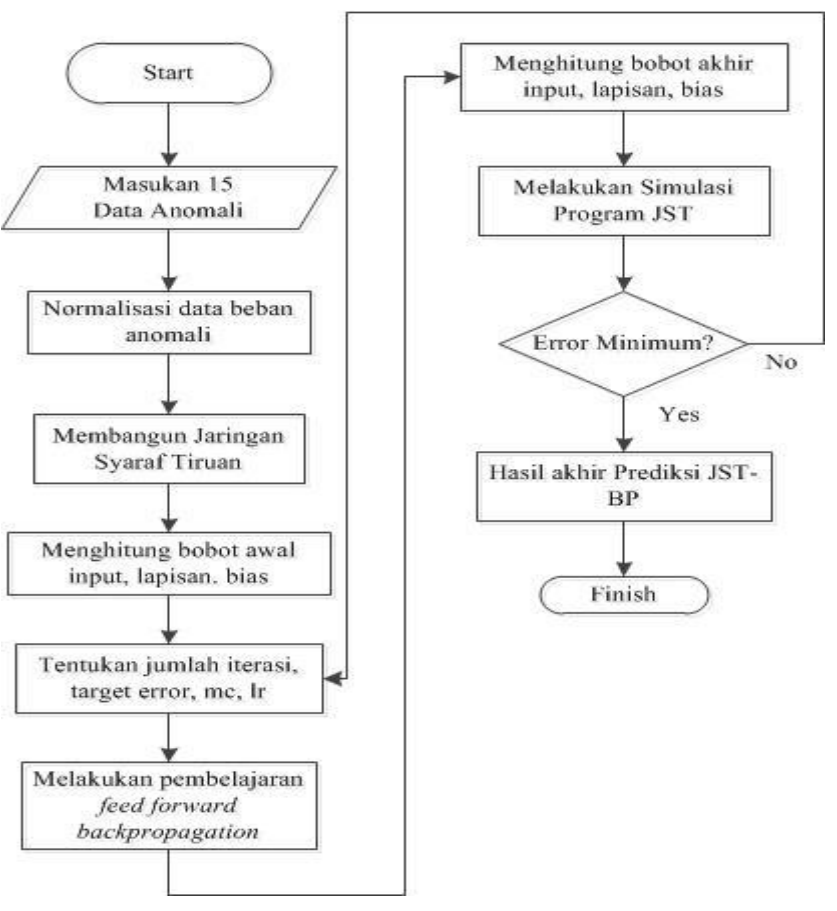

Gambar 1 flowchart algoritma Backpropagation Artifical Neral Network

Diagram alir tersebut dapat dijelaskan sebagai berikut :

Langkah 1 : Masukan data beban anomali, data yang dipakai sebanyak 15 data, 14 data sebagai input dan 1 data sebagai prediksi.

Langkah 2 : Proses normalisasi, dilakukan pada data beban anomali agar nilai-nilai tersebut dapat dihitung dengan nilai yang lebih kecil tanpa kehilangan karakteristik nya.

Langkah 3 : Membangun jaringan syaraf tiruan. Pada algoritma backpropagation menggunakan jaringan feedforward dengan banyak lapisan. Pembejaran yang dipakai sebanyak 4 lapisan 3 sebagai hidden layer dan 1 sebagai output layer. Dengan fungsi aktivasi logsig, tansig, purelin.

Langkah 4 : Mengihitung bobot awal input, lapisan dan bias

\section{Langkah 5}

Menetukan parameter-parameter untuk pelatihan jaringan backpropagation.

Langkah 5 : Melakukan pembelajaran algoritma backpropagation.

Langkah 6 : Menghitung bobot akhir input, lapisan dan bias

Langkah 7 : Melakukan simukasi program jaringan syaraf tiruan

Langkah 8 : Hasil Error minimum? Jika tidak kembali ke langkah 5, jika ya lanjutkan ke langkah 9.

Langkah 9 : Hasil akhir dari prediksi jaringan syaraf tiruan algoritma backpropagation.

Dalam Penelitian ini, kesalahan persentase absolute (MAPE) dianggap sebagai standar pengukuran untuk menguji akurasi dari prediksi. MAPE didefinisikan sebagai [18]

$$
\mathrm{MAPE}=\frac{1}{n} \sum_{i=1}^{n}\left|\frac{Z_{i}-\dot{Z}_{i}}{Z_{i}}\right| x 100
$$

Dimana $Z_{i}$ dan $\mathrm{Z}_{i}$ adalah nilai aktual dan nilai prediksi, sedangkan $\mathrm{n}$ adalah jumlah nilai prediksi.

\section{HASIL DAN PEMBAHASAN}

\section{Karakteristik Penggunaan Beban Listrik Area II Jawa Barat}

Data yang digunakan untuk menganalisis karakteristik penggunaan beban listrik yaitu data pengeluaran beban listrik konsumen Region II Jawa Barat diambil dari data longsheet 2013 sampai 2014. Data tersebut dibagi menjadi 3 tipe yaitu hari kerja (weekday), akhir pekan (weekend) dan libur nasional cuti bersama (holiday) dengan masing-masing data 30 buah.

Pembangkit yang beroperasi di Region 2 Jawa Barat yaitu PLTA (Pangalengan, Lamajan, Cikalong, Bengkok, Parakan, 6 unit Jatiluhur, 4 unit Saguling, 8 unit Cirata), PLTU (Ipp Cirebon, 3 unit Indramayu), PLTG (Sragi, 6 unit Muaratawar), PLTGU (3 unit Bekasi Power, 6 unit Muaratawar, Cikarang), PLTP (4 unit Kamojang, 2 unit Wayang Windu, 3 unit Drajat).

Perbandingan Pola Beban Hari Kerja, Akhir Pekan dan Libur Nasional Cuti Bersama

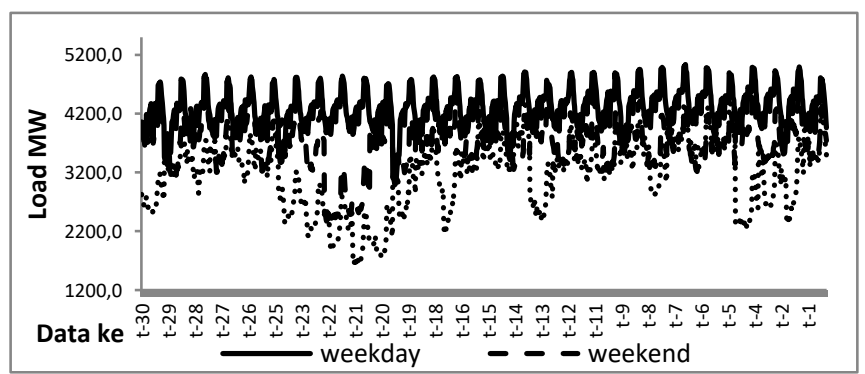

Gambar 2 perbandingan pola beban listrik hari kerja, akhir pekan dan libur nasional cuti bersama 
Gambar 2 memperlihatkan perbandingan antara pola beban weekday, weekend dan holiday. Beban rata-rata untuk hari kerja, akhir pekan, libur nasional dan cuti bersama berturut-turut sebesar 4282,4 MW, 3723,2 MW, 3172,6 MW. Terjadi penurunan penggunaan listrik pada hari libur akhir pekan dan hari libur cuti bersama sebesar $13 \%$ dan $25 \%$ dari beban puncak hari kerja. Pola beban listrik pada hari libur akhir pekan mengalami penurunan tetapi tidak begitu tajam jika dibandingkan dengan hari libur nasional, dikarenakan tidak semua konsumen industri menghentikan kegiatannya sehingga penurunan penggunaan listriknya tidak begitu besar, tetapi di hari libur nasional sebagian sektor industri ada yang tutup sehingga pola pemakaian listrik antara hari nasional cuti bersama dan libur biasa perbedaan nya cukup signifikan. Dari pola tersebut pada setiap data cenderung memiliki karakter yang hampir sama untuk data hari kerja dan akhir pekan tetapi untuk holiday memiliki pola yang berubah-ubah karena adanya beberapa data yang bersifat anomali. Untuk itu diperlukan prediksi beban yang cocok untuk meneliti beban yang bersifat anomali tersebut.

\section{Karakteristik Beban Anomali}

Beban anomali adalah beban yang menyimpang secara signifikan dari beban hari normal [19]. Penelitian kali ini dilakukan pada hari libur nasional cuti bersama yang memiliki tipe beban anomali. Peneliti mengkatagorikan yang termasuk beban anomali yang mempunyai demand $>4000$ MW dan demand < 2000 MW dari pola beban hari libur nasional cuti bersama

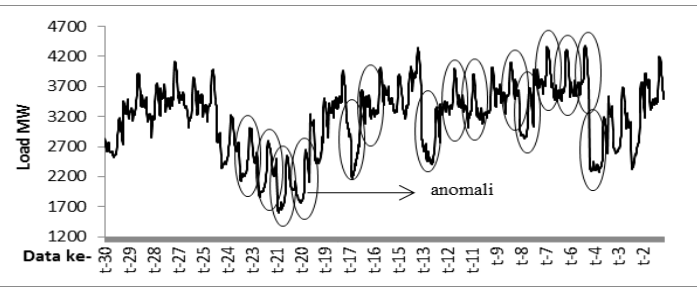

Gambar 3 pola beban anomali dengan sampel 30 holiday

Gambar 3 memperlihatkan pola beban listrik untuk Libur Nasional Cuti Bersama yang memiliki beberapa pola anomali atau ketidaknormalan. Pola tersebut menujukan ketidakteraturan dari pola ke pola berikutnya, sehingga terlihat perbedaan yang cukup signifikan dengan pola hari kerja dan akhir pekan yang memiliki pola yang sama dari hari ke harinya.

Penurunan beban pun terjadi pada beban yang memiliki sifat anomali ini sebesar $46,6 \%$ dari beban minimum weekday dan $32 \%$ dari beban minimum weekend. Sehingga diperlukan prediksi beban listrik secara khusus untuk beban anomali. Rata rata beban puncak nya yaitu $3841 \mathrm{MW}$, terjadi penurunan beban puncak dari weekday, weekend, holiday yang berturut turut sebsar $37 \%, 31 \%$ dan $28 \%$.

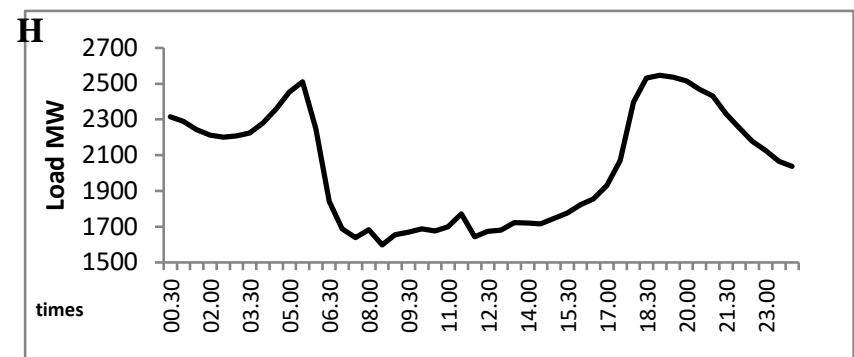

Gambar 4 pola beban anomali dengan jumlah sampel 1 data beban holiday

Gambar 4 memperlihatkan pola beban listrik yang memiliki sifat Anomali pada 07 Agustus 2014 yaitu Hari Libur Nasional (Idul Fitri). Beban rata-rata yaitu 2307,69 MW, beban maksimum yaitu 2791,91 MW pukul 18.30 dan beban minumin 1860,4 MW pukul 08.00.

Pukul 00.30 sampai 05.00 mengalami kenaikan beban secara perlahan tapi tidak begitu tajam hal ini dikarenakan masyarakat mulai bangun dan melakukan berbagai aktivitas. Pukul 05.00 sampai 08.00 beban menurun dengan sangat tajam sebesar $25 \%$ dari beban pada pukul 05.00 . hal ini di karenakan masyarakat sudah mulai keluar untuk melakukan ibadah solat idul fitri dan mulai mematikan penerangan di rumahnya. Pukul 08.00 samapi 16.00 beban mengalami penurunan dari beban rata-rata (08.00-16.00) dari hari kerja, akhir pekan dan holiday (tanpa beban anomali) berturut-turut sebesar 52,1\%, 41,4\%, 28,3\%. Hal ini di karenakan pada hari Raya idul fitri sektor industri sebagian besar tutup. Selanjutunya pukul 16.30 beban mengalami peningkatan sampai pada beban puncak 18.30 hal ini di karenakan masyarakat sudah mulai kembali ke rumah masing masih. 19.00 sampai 20.30 beban masih berada di puncak karena masyarakat sudah mulai melakukan aktivitas. Selanjutnya 21.00 sampai 24.00 beban mulai menurun karena masyarakat sudah mulai beristirahat.

Pembangkit yang beroperasi yaitu PLTA (Pangalengan, Lamajan, Cikalong, Bengkok, Prkan, 3 Unit Jatiluhut), PLTU (Ipp Cirebon, Indramayu), PLTGU (Bekasi Power, Cikarang, 4 Unit Muaratawar), PLTP (kamojang, Wayang Windu, 1 unit Drajar). Pembangkit yang $O F F$ sepanjang hari yaitu PLTP (2 Unit Drahat), PLTGU (2 unit Muaratawar), PLTG (Muaratawar), PLTU (Indramayu). Pembangkit yang ON/OFF yaitu PLTG (sragi), PLTA (3 Unit Jatiluhur, Cirata

Hasil Prediksi Beban Listrik menggunakan Algoritma Feed Forward Backpropagation Jaringan Syaraf Tiruan

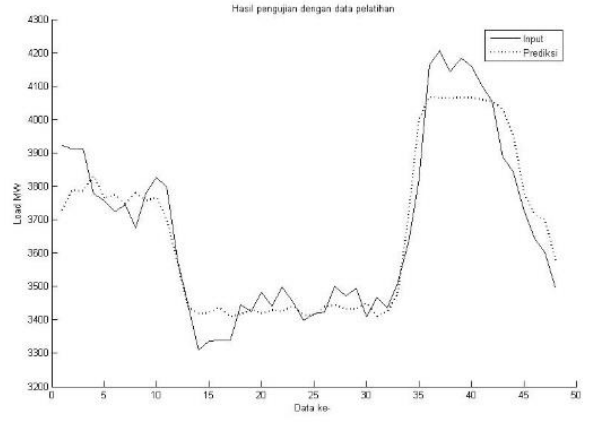

Gambar 5 hasil pengujian dengan data pelatihan 
Gambar 5 memperlihatkan hasil pengujian dengan data pelatihan algortima backpropagation Hasil Mean Squared Error (MSE) dari running algoritma backpropagation pada data target yaitu $0,1 \%$ sedangkan nilai persentase kesalahan absolut rata-rata (MAPE) yang diperoleh backpropagation adalah $1,74 \%$.

\section{Optimasi Learning Rate}

Tabel 1 memperlihatkan hasil eksperimen optimasi nilai learning rate yang bervariasi pada beban listrik yang berrsifat anomali.

Tabel 1 hasil eksperimen variasi learning rate

\begin{tabular}{lcc}
\hline \multicolumn{3}{l}{ Hasil Eksperimen Variasi Learning Rate } \\
\hline No & learning rate $(\alpha)$ & MAPE \% \\
\hline 1 & 0,1 & 1,68 \\
2 & 0,2 & 1,67 \\
3 & 0,3 & 1,68 \\
4 & 0,4 & 1,81 \\
$\mathbf{5}$ & $\mathbf{0 , 5}$ & $\mathbf{1 , 4 9}$ \\
6 & 0,6 & 1,70 \\
7 & 0,7 & 1,89 \\
8 & 0,8 & 1,77 \\
9 & 0,9 & 1,66 \\
\hline
\end{tabular}

Tabel 1 memperlihatkan hasil optimasi nilai learning rate pada beban listrik yang bersifat anomali di plot pada rentang 0,1 sampai 0,9. Dari hasil eksperimen di dapat bahwa hasil eksperimen nilai learning rate terbaik untuk beban listrik anomali yaitu 0,5 dengan rata-rata error $1,49 \%$. Sehingga pemilihan nilai learning rate untuk mendapatkan tingkat akurasi yang terbaik dapat dipilih nilai learning rate yang tidak besar maupun kecil tetapi di tengah-tengah rentang tersebut. Jika melihat hasil optimasi pada nilai learning rate yang lain, nilai yang diperoleh perbedaannya tidak begitu jauh seperti dapat dilihat dari nilai error terbesar pada learning rate 0,7 yaitu 1,89 yang memiliki selisih 0,4 dari nilai learning rate terkecil. Sehingga dapat disimpulakan bahwa variasi nilai learning rate tidak begitu berpengaruh pada proses prediksi beban listrik.

\section{Optimasi Jumlah Input}

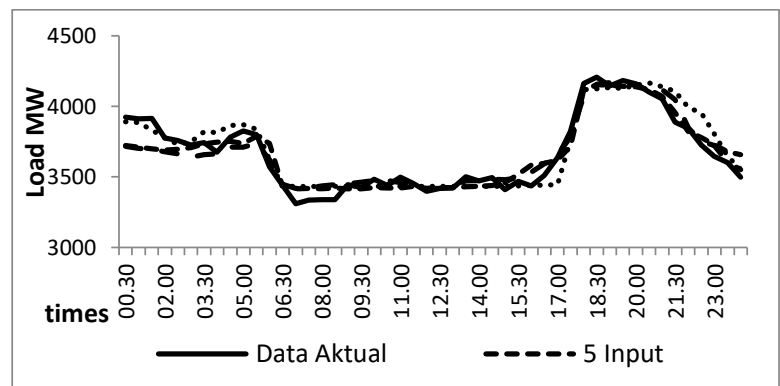

Gambar 6 hasil prediksi beban listrik anomali dengan variasi jumlah input

Gambar 6 memperlihatkan hasil optimasi pada beban listrik yang bersifat anomali dengan input pembelajaran yang bervariasi yaitu 5 input, 10 input dan 14 input. Hasil prediksi beban listrik untuk 5 input menghasilkan rata rata error 1,73\%. Hasil error yang dihasilkan dengan pembelajaran 5 input ini memiliki selisih 0,13 dengan hasil pembelajaran 14 input. Hasil prediksi beban listrik untuk 10 input menghasilkan rata-rata error $1,70 \%$. Hasil error yang dihasilkan memiliki selisih secara berturut-turut 0,3 dan 0,10 dari hasil error pembelajaran 5 input dan 14 input, sehingga jumlah input mempengaruhi hasil dari prediksi.

\section{Optimasi Jumlah Input}

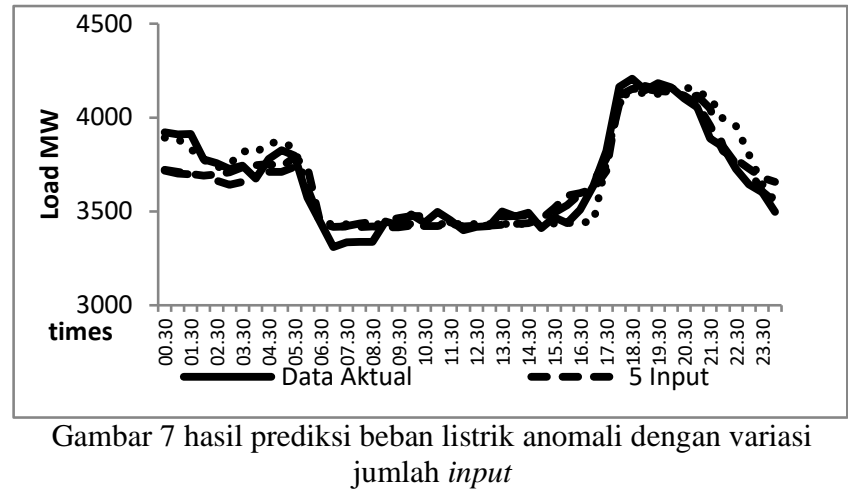

Gambar 7 memperlihatkan hasil optimasi pada beban listrik yang bersifat anomali dengan input pembelajaran yang bervariasi yaitu 5 input, 10 input dan 14 input. Eksperimen dilakukan dengan menggunakan 4 hidden layer dengan fungsi aktivasi sigmoid biner, sigmoid biopolar, sigmoid biopolar.

Hasil prediksi beban listrik untuk 5 input menghasilkan rata rata error $1,73 \%$. Hasil error yang dihasilkan dengan pembelajaran 5 input ini memiliki selisih 0,13 dengan hasil pembelajaran 14 input. Hasil prediksi beban listrik untuk 10 input menghasilkan rata rata error $1,70 \%$. Hasil error yang dihasilkan memiliki selisih secara berturut-turut 0,3 dan 0,10 dari hasil error pembelajaran 5 input dan 14 input, sehingga jumlah input mempengaruhi hasil dari prediksi.

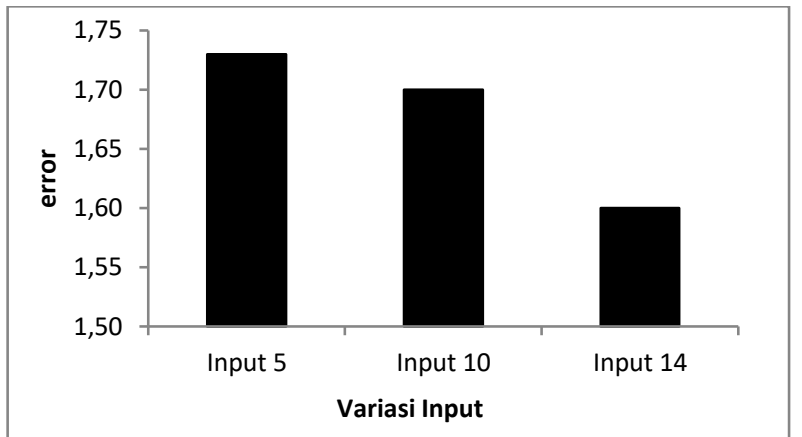

Gambar 8 perbandingan error variasi input

Gambar 8 memperlihatkan perbandingan error antar input 5, 10 dan 14. Dari grafik dapat disimpulkan bahwa semakin banyak data dibelajarkan maka tingkat akurasi semakin baik dengan jumlah error semakin kecil. Adapun terjadinya perbedaan aktivasi antara data pembelajaran 10 input dan 12 input masih dapat ditoleransi karena selisihnya tidak begitu jauh. 


\section{KESIMPULAN}

Penelitian ini menunjukan bahwa performa algoritma feed forward backpropagation jaringan syaraf tiruan untuk prediksi beban lisrik hari libur tipe beban anomali menunjukan tingkat akurasi yang tinggi. Untuk mencapai hasil yang maksimal optimasi dilakukan dengan mengubah nilai learning rate dan jumlah input. Hasil optimasi membuktikan bahwa jumlah input berpengaruh pada tingkat akurasi dari prediksi beban listrik hari libur tipe beban anomali. Semakin banyak jumlah input pembelajaran maka semakin tinggi tingkat akurasi dan menunjukan error yang semakin kecil. Variasi learning rate membuktikan bahwa nilai learning rate pada nilai tengah memberikan hasil terbaik.

\section{REFERENSI}

[1] R. Behera, B. P. Panigrahi, and B. B. Pati, “A Hybrid Short Term Load Forecasting Model of an Indian Grid," vol. 2011, no. May, pp. 190-193, 2011.

[2] A. K. Choobeh, "Short Term Load Forecasting for Shiraz Region Using Adaptive Back Propagation Neural Network," vol. 22, no. Iccms, pp. 54-57, 2012.

[3] A. Gupta and P. K. Sarangi, "Electrical Load Forecasting using Genetic Algoritthm Based Backpropagation Metod," vol. 7, no. 8, pp. 10171020, 2012.

[4] P. D. Matthewman and H. Nicholson, "Techniques for load prediction in the electricity-supply industry," Proceedings of the Institution of Electrical Engineers, vol. 115, no. 10. p. 1451, 1968.

[5] W. R. Christiaanse, "Short-Term Load Forecasting Using General Exponential Smoothing," IEEE Trans. Power Appar. Syst., vol. PAS-90, no. 2, 1971.

[6] M. T. Hagan and S. M. Behr, "The Time Series Approach to Short Term Load Forecasting," IEEE Transactions on Power Systems, vol. 2, no. 3. pp. 785-791, 1987.

[7] G. Lambert-Torres, "Short-term load forecasting using a fuzzy engineering tool," pp. 36-40, 1991.

[8] K. Y. Lee, Y. T. Cha, and J. H. Park, "Short-term load forecasting using an artificial neural network," Power Syst. IEEE Trans., vol. 7, no. 1, pp. 124132, 1992.

[9] P.-Y. W. P.-Y. Wang and G.-S. W. G.-S. Wang, "Power system load forecasting with ann and fuzzy logic control," Proc. TENCON '93. IEEE Reg. 10 Int. Conf. Comput. Commun. Autom., no. 0, 1993.

[10] H.-T. Yang, C.-M. Huang, and C.-L. Huang, "Identification of ARMAX model for short term load forecasting: an evolutionary programming approach," Power Systems, IEEE Transactions on, vol. 11, no. 1. pp. 403-408, 1996.

[11] M. Y. Cho, J.-C. Hwang, and C.-S. Chen, "Customer short term load forecasting by using ARIMA transfer function model," Energy
Management and Power Delivery, 1995. Proceedings of EMPD '95., 1995 International Conference on, vol. 1. pp. 317-322 vol.1, 1995.

[12] H. Mori, Y. Sone, D. Moridera, and T. Kondo, "Fuzzy inference models for short-term load forecasting with tabu search," IEEE SMC'99 Conf. Proceedings. 1999 IEEE Int. Conf. Syst. Man, Cybern. (Cat. No.99CH37028), vol. 6, 1999.

[13] R. R. B. de Aquino, A. A. Ferreira, M. M. S. Lira, G. B. Silva, O. N. Neto, J. B. Oliveira, C. F. Diniz, and J. Fideles, "A Hybrid Intelligent System for Short and Mid-term Forecasting for the CELPE Distribution Utility," 2006 IEEE Int. Jt. Conf. Neural Netw. Proc., 2006.

[14] R. Dica, C (SC C-Tech SRL, Constanta, "Wind power short-term forecasting system," PowerTech, 2009 IEEE Bucharest, pp. 1-7, 2009.

[15] C. Liu and F. Liu, "The short-term load forecasting using the kernel recursive least-squares algorithm," 2010 3rd Int. Conf. Biomed. Eng. Informatics, no. Bmei, pp. 2673-2676, 2010.

[16] M. Lin, "Power Prediction Model of GridConnected Photovoltaic and Power Flow Analysis," Power Energy Eng. Conf. (APPEEC), 2012 AsiaPacific, pp. 1-4, 2012.

[17] S. Arora and J. W. Taylor, "Short-Term Forecasting of Anomalous Load Using Rule-Based Triple Seasonal Methods," vol. 28, no. 3, pp. 3235-3242, 2013.

[18] N. Mohamed and M. H. Ahmad, "Forecasting Short Term Load Demand Using Multilayer Feedforward ( MLFF ) Neural Network Model," vol. 6, no. 108, pp. 5359-5368, 2012.

[19] S. Arora, J. W. Taylor, and P. E. Street, "IIF-SAS Report Load Forecasting for Special Days Using a Rule-based Modeling Framework : A Case Study for France Load Forecasting for Special Days Using a Rule-based Modeling Framework : A Case Study for France," pp. 1-39. 


\section{BIOGRAFI PENULIS}

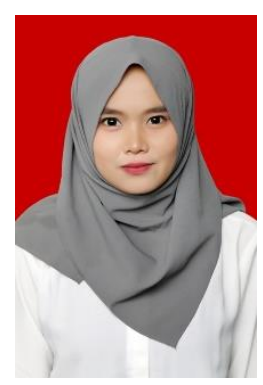

Linda Faridah, lahir di Bandung pada tanggal 17 Maret 1995. Saat ini bertugas sebagai dosen di Jurusan Teknik Elektro, Universitas Siliwangi. Bidang penelitian yang ditekuni saat ini yaitu Sistem Tenaga Listrik, renewable energy.

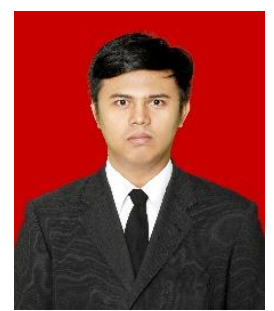

Imam Taufiqurrahman, lahir di Bandung pada tanggal 12 juni 1990, saai ini bertugas sebagai staf pengajar di Jurusan Teknik Elektro,Universitas SIliwangi, bidang penelitian yang ditekuni saat ini adalah Otomasi, Robotika dan Sistem Cerdas.

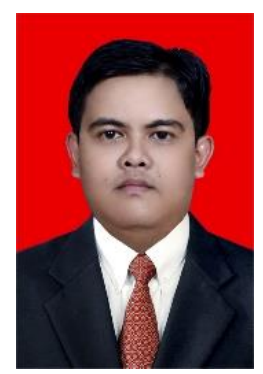

Muhammad Aris Risnandar, lahir di Ciamis pada tanggal 10 April 1988. Saat ini bertugas sebagai dosen di Jurusan Teknik Elektro, Universitas Siliwangi. Bidang penelitian yang ditekuni saat ini yaitu Sistem Tenaga Listrik dan Sistem Distribusi.

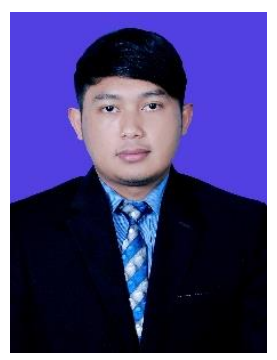

Andri Ulus Rahayu, lahir di Bandung pada tanggal 03 April 1989. Saat ini bertugas sebagai dosen di Jurusan Teknik Elektro, Universitas Siliwangi. Bidang penelitian yang ditekuni saat ini yaitu Sistem kendali, IoT, Sistem Komputer 